\title{
The Atlantic and summer Pacific waters variability in the Arctic Ocean from 1997 to 2008
}

\author{
Pascaline Bourgain ${ }^{1}$ and Jean Claude Gascard ${ }^{1}$ \\ Received 20 January 2012; revised 7 February 2012; accepted 7 February 2012; published 6 March 2012.
}

[1] As a main source of heat for the Arctic Ocean, the Atlantic and Summer Pacific waters and their spatiotemporal variability require serious attention especially in the context of a drastic summer sea ice extent decrease. We propose to examine the recent evolution of these two water masses at a larger spatial scale than what was done so far. For that purpose, we introduced indices that proved to be efficient tools for quantifying water masses influence. Based on these indices and thanks to a very large data set collected throughout the Arctic deep basin from 1997 to 2008, we investigated the interannual variability of the Atlantic and Summer Pacific waters distribution and characteristics. Observations confirmed the existence of warm pulses of the Atlantic water mass propagating into the Arctic basin. However, no warming trend of the Atlantic water in the Eurasian basin was identified over the 1997-2008 time period. In contrast, the Summer Pacific water was getting warmer during the same period. The Summer Pacific water of the Canadian basin, being closer to the surface than the Atlantic water mass and exhibiting a warming trend, appears to be a serious candidate for contributing partly to the drastic summer sea ice extent and thickness decrease observed recently in the Arctic and in the Canadian basin in particular. Citation: Bourgain, P., and J. C. Gascard (2012), The Atlantic and summer Pacific waters variability in the Arctic Ocean from 1997 to 2008, Geophys. Res. Lett., 39, L05603, doi:10.1029/2012GL051045.

\section{Introduction}

[2] The Arctic Ocean is exposed to oceanic advection that influences the heat and salt balance. The warm and salty Atlantic water, entering the Arctic Ocean through Fram Strait and the Barents Sea, and the warm and relatively fresh Summer Pacific water, entering from the North Pacific through Bering Strait, constitute major heat sources for the Arctic Ocean. These water masses are located in the water column at 300-500 meters depth and 50-80 meters depth respectively. Their potential impact on the sea ice mass balance and their possible implication in the recent drastic summer sea ice extent decrease are relevant questions. According to Polyakov et al. [2010b], the "warming" of the Atlantic water (AW) has an impact on the "overlying" upper layers in the Eurasian basin. In the Canada basin, Shimada et al. [2006] suggested that the Summer Pacific water (SPaW) can be held responsible for a surface preconditioning of the drastic summer sea ice retreat observed recently in the Western Canadian basin. Jackson et al. [2010] and Toole et al. [2010] have shown that

${ }^{1}$ LOCEAN, Université Pierre et Marie Curie, Paris, France.

Copyright 2012 by the American Geophysical Union. 0094-8276/12/2012GL051045 in another region of the Central Canadian basin, the ocean surface layer in direct contact with the atmosphere has the capacity to affect the sea ice mass balance by storing extra heat from incoming solar radiation.

[3] The AW and SPaW have a strong time and space variability. Observations from the 1990s documented positive AW temperature anomalies of up to $1^{\circ} \mathrm{C}$ [Quadfasel et al., 1991] and a warming signal of the AW in the Eurasian basin was observed in the 2000s [Polyakov et al., 2005; Ivanov et al., 2009]. The Pacific waters are also subjected to large interannual variability. Woodgate et al. [2010] observed a strong warming and freshening at mooring sites in the Bering Strait in the 2000s, and pointed out that the 2007 heat flux was twice as much as the 2001 heat flux and would be enough to melt one third of the 2007 summer Arctic sea ice loss. Finally, the extent of the respective area occupied by the $\mathrm{AW}$ and $\mathrm{SPaW}$ in the Arctic Ocean changed with time too. In the early 1990s, the boundary of the SPaW into the deep Arctic basin moved from the Lomonosov ridge back to the Mendeleyev ridge [McLaughlin et al., 1996].

[4] It is clear that a better understanding of the current situation in the Arctic can't be achieved without a good knowledge about space and time variability of the AW and $\mathrm{SPaW}$ distribution and characteristics. Thanks to a large data set collected in recent years, we were able to examine these two water masses at a larger spatial scale than was done before. For this purpose, we will first introduce indices in order to better qualify and quantify the characteristics and distribution of both the AW and the SPaW spreading into the Arctic Ocean. Then, we will describe some general features related to these two water masses before evaluating their space and time variability over the 1997-2008 time period in the Arctic Ocean.

\section{Data and Method}

[5] More than 16000 CTD vertical profiles, including data from icebreaker campaigns, drifting platforms, aerial surveys and submarine cruises, were collected over the deep Arctic Ocean from 1997 to 2008 (including the 4th IPY) (Figure 1). For the analysis, we used the Kriging interpolation method which is an improved and advanced interpolation method as it minimizes error covariance. This method allowed us to produce maps of several parameters on a $1^{\circ}$ longitude* $0.5^{\circ}$ latitude grid using the whole data set split into three time periods: 1997-2002 (period 1, P1), 2003-2006 (period 2, P2) and 2007-2008 (period 3, P3). This combination appeared to be the best compromise to get the best time and space resolution from this data set over this period (see auxiliary material). ${ }^{1}$

\footnotetext{
${ }^{1}$ Auxiliary materials are available in the HTML. doi:10.1029/
} 2012GL051045 

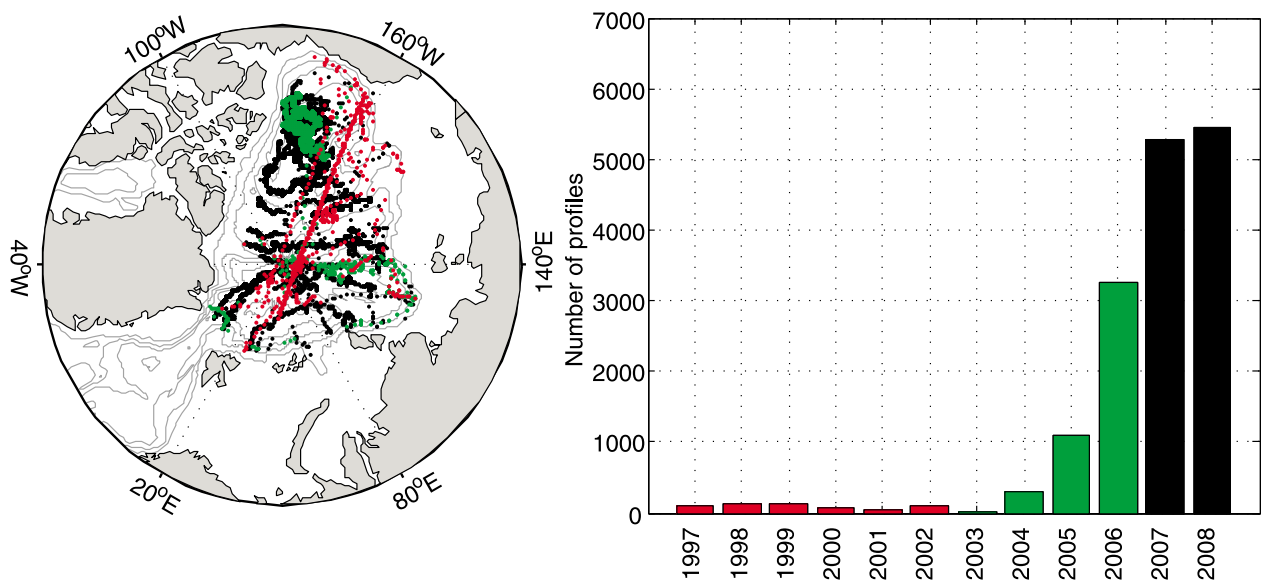

Figure 1. (left) Spatial distribution of the data set and (right) histogram of the annual data distribution.

[6] Because this paper focuses on the heat sources of the Arctic Ocean and their potential impact on the sea ice mass balance, we chose not to include the Winter Pacific water and the Barents Sea Branch of the AW in our analysis since these two water masses are both colder and deeper than the $\mathrm{SPaW}$ and the Fram Strait Branch of the AW respectively. Consequently, they are less influential on the surface heat budget for melting ice. Indices were created to quantify the influence of both AW (AWI: Atlantic Water Index) and SPaW (PWI: summer Pacific Water Index) (Figure 2). The AW temperature maximum being highly correlated with the AW heat content (we obtained a correlation coefficient of $\mathrm{R}=0.92$ ), we used the AW temperature maximum to define the AWI. The temperature maximum is the most commonly used parameter characterising the AW, and it is documented by a large number of CTD observations. In the literature, the SPaW was identified through chemical tracers or salinity constant [Jones et al., 1998; Shimada et al., 2006]. We defined the SPaW as a temperature maximum based on four distinct criteria: 1) The SPaW temperature maximum is deeper than $40 \mathrm{dbar}$ to ensure that it is distinct from the Near Surface Temperature Maximum (NSTM) [Jackson et al.,
2010] that could be present in the upper part of the water column above $40 \mathrm{dbar}$ due to seasonal solar heating. The $\mathrm{SPaW}$ temperature maximum is also shallower than the top of the thermocline detected as the first local maximum of the second derivative versus depth of the temperature vertical distribution encountered above the AW core. The top of the thermocline is usually located around $80-100$ dbar in the Eurasian basin and around 180-200 dbar in the Canadian basin. 2) The SPaW temperature maximum must correspond to a layer with a minimum thickness of 5 dbar to avoid temperature spikes. The layer thickness is measured between two temperature minima located just above and below the temperature maximum. The upper minimum might either correspond to brines influence or to the maximum depth reached by winter mixed layer. The lower minimum might either correspond to brines or to winter Pacific water. 3) The SPaW temperature maximum we are looking for falls within the salinity range [31 psu $33 \mathrm{psu}]$. 4) The SPaW temperature maximum is at least $0.16^{\circ} \mathrm{C}$ above the freezing temperature (function of both salinity and pressure). This temperature difference was chosen because it is one standard deviation greater than the difference between the Nansen basin "Cold

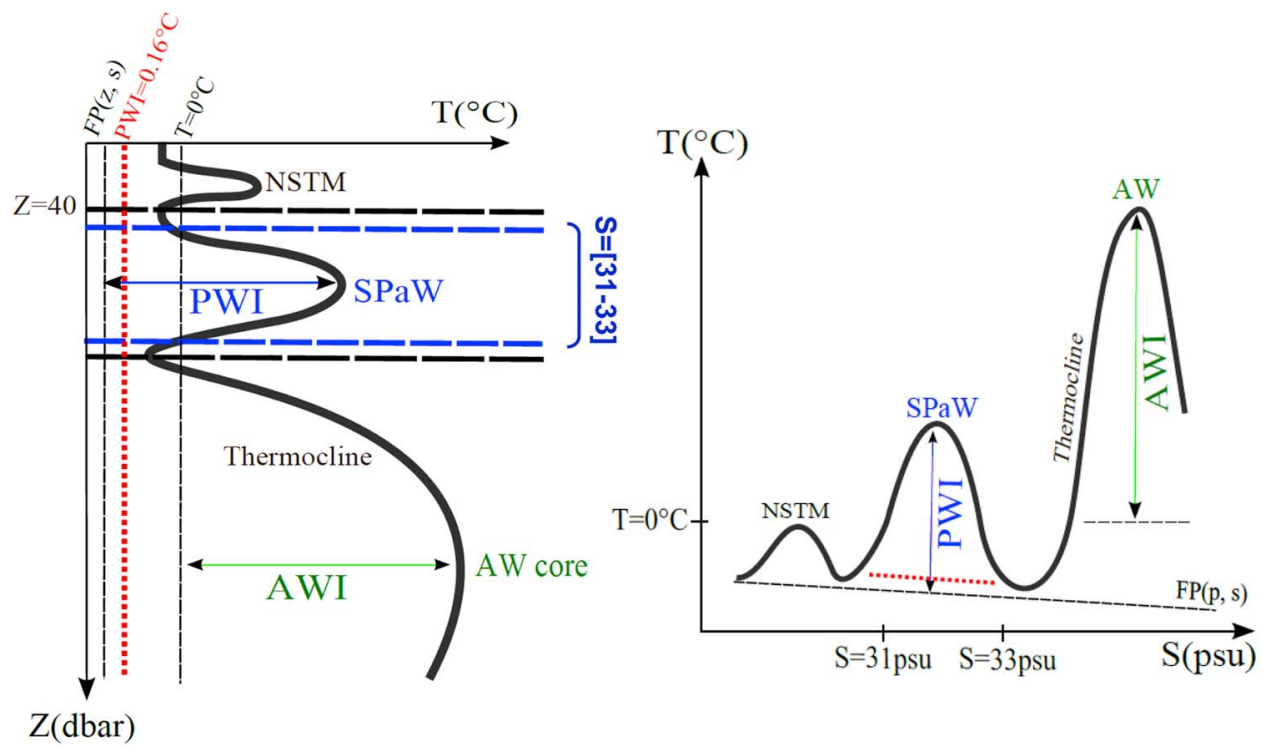

Figure 2. AWI and PWI definition displayed both on (left) a temperature profile and (right) a temperature-salinity diagram. 

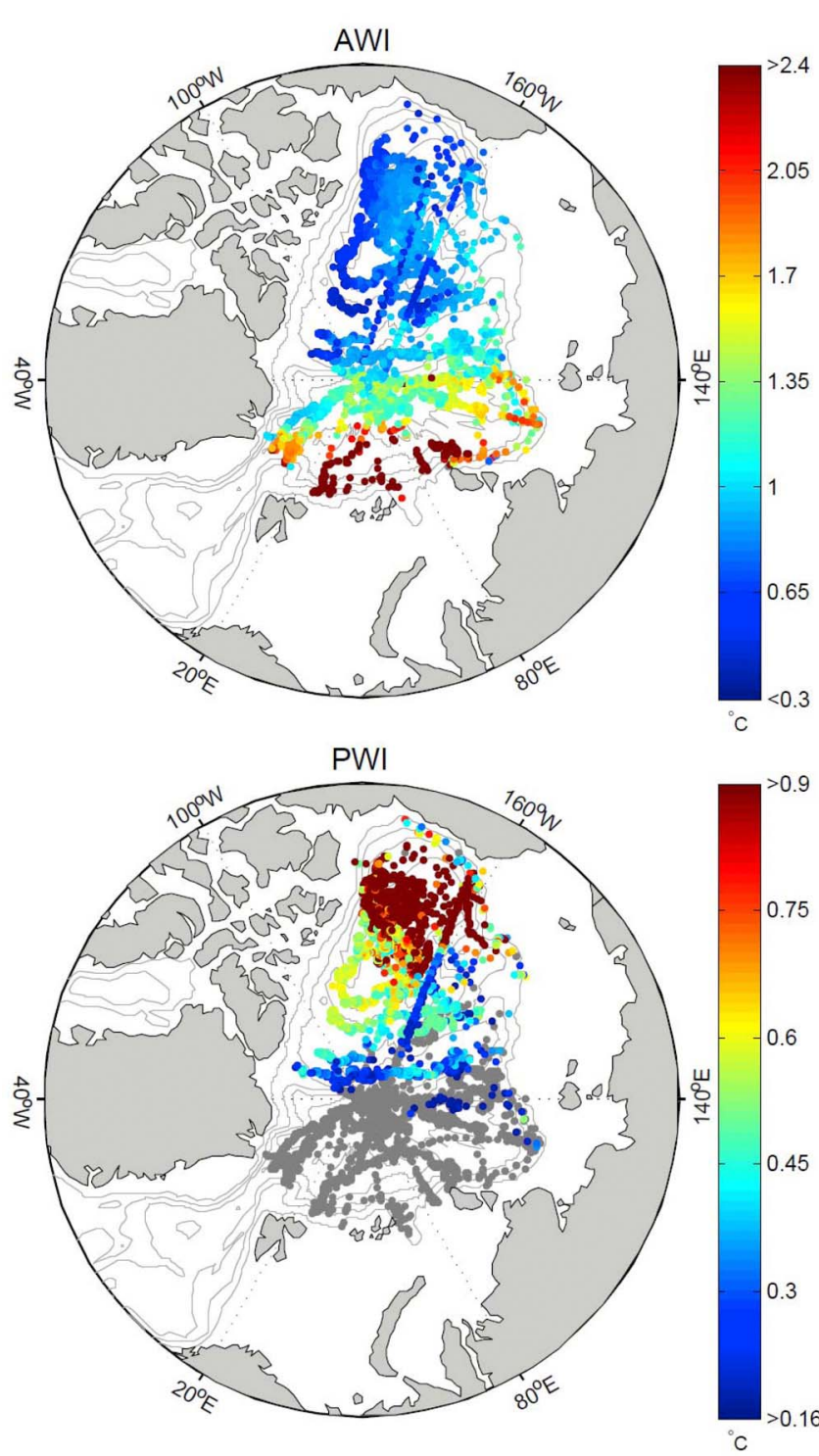

Figure 3. (top) AWI and (bottom) PWI spatial distribution. Grey areas correspond to the regions where there is no SPaW.

Halocline" [Aagaard et al., 1981] temperature and the freezing point within the range [31 psu $33 \mathrm{psu}]$ and at depth greater than 40 dbar. PWI was then defined as the difference between the SPaW temperature maximum and the corresponding freezing point.

\section{Results}

\subsection{AW and SPaW General Features}

[7] In this section, the data were analysed on a steady state basis covering the 11 years of observations. Understandably, Figure 3 illustrates that AWI (PWI) was decreasing when moving away from Fram Strait (Bering Strait) due to diffusion processes and exchanges between $\mathrm{AW}(\mathrm{SPaW})$ and surrounding colder water masses of Polar origins. In contrast with the AW that can be observed everywhere in the deep Arctic basin, the SPaW was not present in the Eurasian basin. Note that a very small number of profiles in the
Eurasian basin evidenced small PWI values (above the $0.16^{\circ}$ C threshold), which illustrates the limit of the PWI index sensitivity, based on temperature and salinity, to clearly identify SPaW. Since the Eurasian basin is also the region where the AW is the warmest, the highest AWI distribution overlaps the lowest PWI distribution. That creates a remarkable boundary between the two domains influenced by AW or SPaW respectively although these two water masses circulate at different depth levels. This boundary, also defined by McLaughlin et al. [1996] as separating the "Eastern Arctic assembly" (absence of SPaW and warm AW core) from the "Western Arctic assembly" (presence of $\mathrm{SPaW}$ and cold AW core), was prone to time and space variability. On average, during the 11-year period, this boundary was located in the Makarov basin.

\subsection{AW and SPaW Variability Over the Last Decade (1997-2008)}

\subsubsection{AW Warm Anomalies in the Eurasian Basin}

[8] In the Eurasian basin, North East of Svalbard, AWI increased from $\mathrm{P} 1$ to $\mathrm{P} 2$ by $0.74^{\circ} \mathrm{C}$ (Figure 5, top, see arrows), and farther downstream along the AW pathway, from $\mathrm{P} 2$ to $\mathrm{P} 3$, by $0.65^{\circ} \mathrm{C}$. These warming events might be one and the same event observed at different locations according to the propagation time. Extreme warm AW events were observed before. Orvik and Skagseth [2005] observed remarkable events characterized by significant temperature increase of the Norwegian Atlantic current followed by a gradual decrease. Polyakov et al. [2005] pointed out the link between polar and sub-polar Arctic basins to explain the $0.8^{\circ} \mathrm{C}$ "pulse-like" warming signal observed in 2004 east of Svalbard, also detected by Ivanov et al. [2009] at $30^{\circ} \mathrm{E}$ in 2006 . It might be the same event we described here. Assuming that the warming episodes detected in the Nansen basin are related to warm pulse-like events advected along the AW pathway, we estimated a lower bound for the mean AW flow speed to be $0.57 \mathrm{~cm} / \mathrm{s}$. For comparison, Polyakov et al. [2005] estimated it at $\sim 1.5 \mathrm{~cm} / \mathrm{s}$.

\subsubsection{AW Warm Anomaly in the Beaufort Gyre}

[9] In 1998, the presence of "Warm Atlantic Water", first observed in the early 1990s in the Nansen basin [Quadfasel et al., 1991], was identified in the Northern and Western side of the Chukchi Plateau [McLaughlin et al., 2004; Shimada et al., 2004]. Thermohaline intrusions of AW mixing with cold ambient Canadian water were reported by McLaughlin et al. [2004] to identify this phenomenon. In contrast with observations taken during P1, observations from year 2005 (during P2) taken in the Beaufort gyre revealed the presence of thermohaline intrusions with temperature-salinity structures similar to those described by McLaughlin et al. $\left(\sim 0.3 \mathrm{psu} /{ }^{\circ} \mathrm{C}\right)$. Therefore, we interpreted the $\mathrm{AW}$ warming observed in the Beaufort Gyre during P2 (Figure 4, top middle and Figure 5, top left) as a manifestation of the "Warm Atlantic Water" intruding in that region during that period. That would correspond to a mean travel time of 15 years from Fram Strait up to the Beaufort Sea, fitting with the estimation by Karcher and Oberhuber [2002] of the time needed for the AW to return to Fram Strait (30 years) following the continental slope of the Eurasian and Canadian basins.

3.2.3. SPaW Warming Episode in the Canadian Basin

[10] From P1 to P2, the SPaW temperature increased in the southern Canadian basin by $0.55^{\circ} \mathrm{C}$ (Figure 5, bottom, 

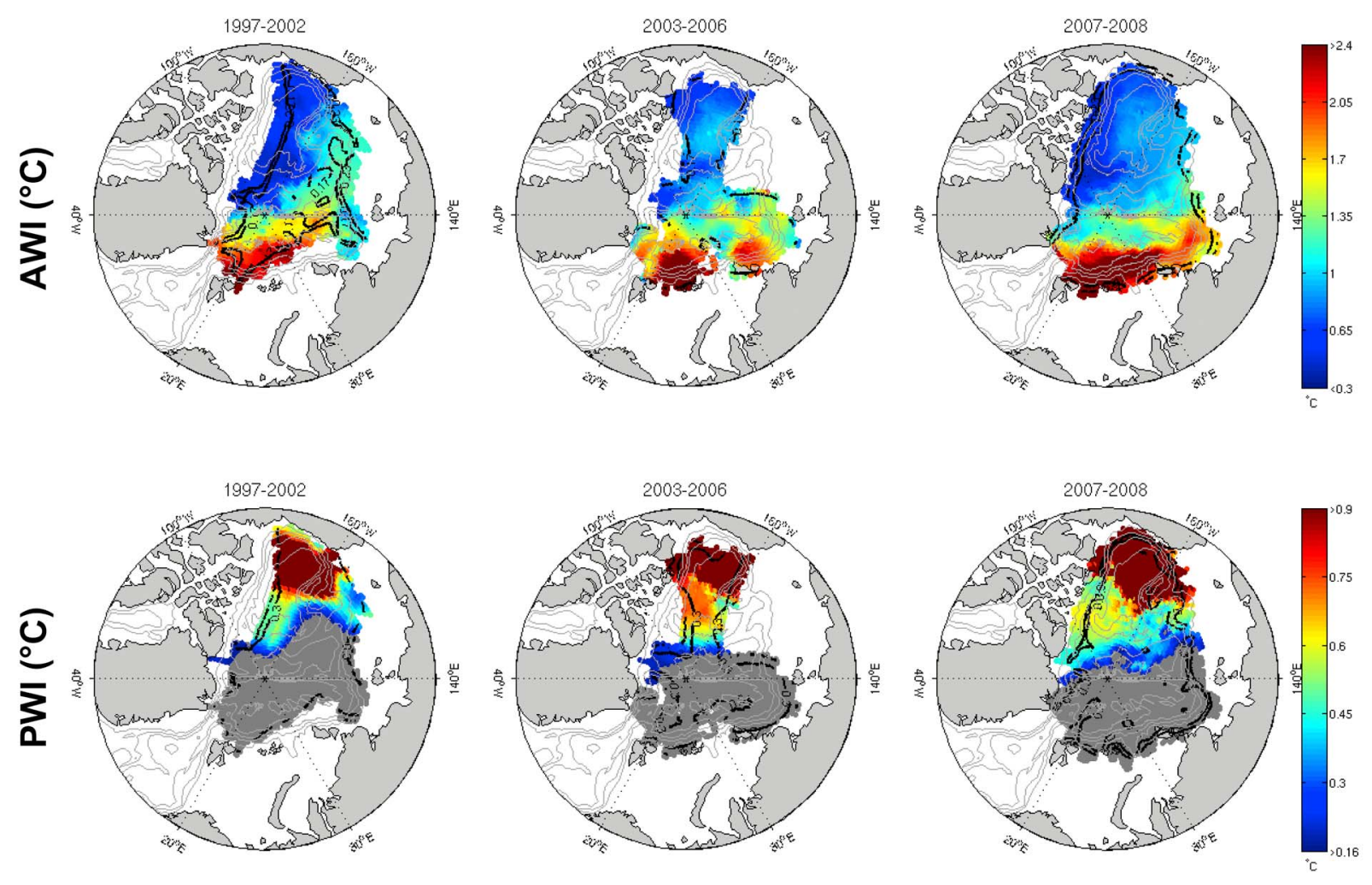

Figure 4. Evolution of the (top) AWI and (bottom) PWI spatial distribution over the three time periods. Black dashed isolines correspond to estimation error $(\sigma)$ due to Kriging interpolation process. The isolines represented are $\sigma=0.17^{\circ} \mathrm{C}$ and $\sigma=$ $0.23^{\circ} \mathrm{C}$ for AWI, and $\sigma=0.30^{\circ} \mathrm{C}$ and $\sigma=0.36^{\circ} \mathrm{C}$ for PWI. Grey areas correspond to the regions where there is no SPaW.

see arrow). North of this early SPaW warming event, another $0.43^{\circ} \mathrm{C}$ warming event was evidenced from $\mathrm{P} 2$ to P3. More likely, these two warming events were one and the same event propagating across the Canadian basin. This might also correspond to the strong heat flux episode observed in late 2004 in Bering Strait by Woodgate et al. [2010]. Based on these observations, we could estimate the minimum value of the $\mathrm{SPaW}$ mean advection speed in the Canadian basin to be about $0.3 \mathrm{~cm} / \mathrm{s}$, which is in agreement with the estimates of the subsurface waters flowing usually at $\sim 1 \mathrm{~cm} / \mathrm{s}$ at $100 \mathrm{~m}$ depth, in the Canadian basin, according to Morison et al. [1998].

\subsubsection{AW and SPaW Trends and Long-Term Variability}

[11] Besides the time and space variability of AWI in the Arctic Ocean, no global trend could be detected over the 1997-2008 time period in the Eurasian basin, in contrast with what Polyakov et al. [2005] suggested. However, this absence of trend in our analysis might be due to a shorter time series (11 years) compared to other studies based on a multidecadal time scale analysis ( 80 years) of the Northern Atlantic Ocean [Polyakov et al., 2010a].

[12] Based on our analysis, PWI increased in the Canadian basin from $0.30^{\circ} \mathrm{C}\left( \pm 0.21^{\circ} \mathrm{C}\right)$ during $\mathrm{P} 1$ to $0.66^{\circ} \mathrm{C}$ $\left( \pm 0.18^{\circ} \mathrm{C}\right)$ during $\mathrm{P} 3$. This is coherent with Woodgate et al. [2010] noticing a strong warming trend starting in 2001 in the Bering Strait. We can conclude that the upper layers of the Canadian basin underwent a warming trend since the early 2000s that could have had a significant impact on the surface heat budget ultimately contributing to an enhanced sea ice melt in that region.

\section{Conclusion}

[13] Thanks to a very large data set collected in the Arctic Ocean from 1997 to 2008, an analysis of the distribution and characteristics of the AW and SPaW, the two main sources of heat for the Arctic Ocean, was realised during this period characterized by drastic changes in sea ice cover. Two indices, PWI and AWI, are proposed to identify and characterize these water masses in the Arctic Ocean and to evaluate their space and time variability during this period.

[14] Our analysis confirmed that warm pulses of the AW propagated into the Arctic Ocean during the 11 years period, in agreement with Polyakov et al. [2005] who observed a "pulse-like" warming signal in the Eurasian basin. In addition, the warm AW pulse first detected in the Nansen basin in the early 1990s [Quadfasel et al., 1991], was identified in the Beaufort Gyre in 2005 implying a travel time of 15 years. Despite the existence of warm pulses, no warming trend of the AW in the Eurasian basin was identifiable over the 1997-2008 time period, in contrast with Polyakov et al. [2010a].

[15] Our observations also revealed that the warm signal reported in the Bering Strait in 2004 [Woodgate et al., 2010] propagated in the interior of the Canada basin during the mid and late 2000s and that the temperature of the SPaW increased over the 1997-2008 time period. 

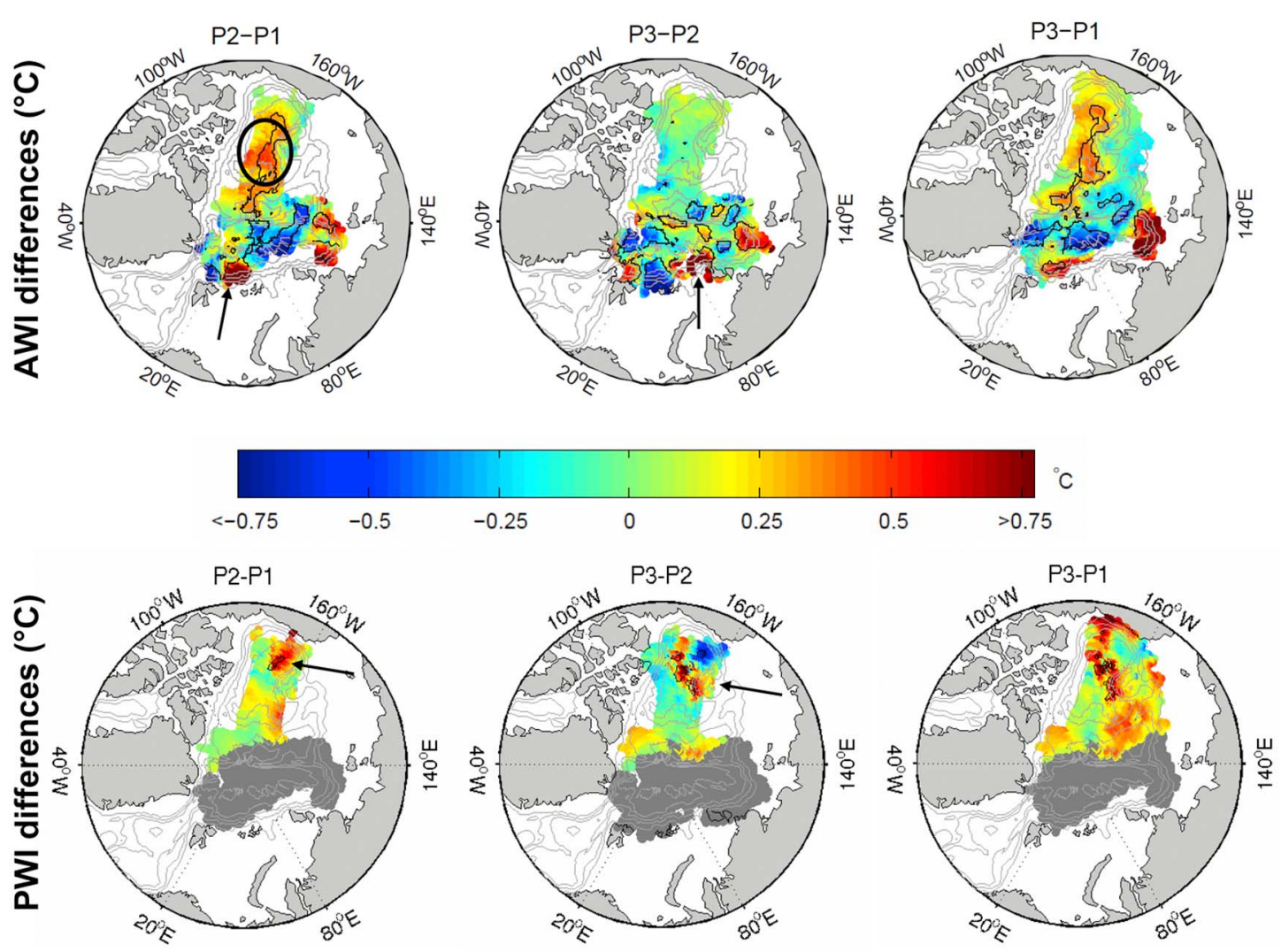

Figure 5. (top) AWI and (bottom) PWI differences (left) from P1 to P2, (middle) from P2 to P3 and (right) from P1 to P3. Blue/red colours correspond to a decrease/increase in time of the index. Black isolines correspond to $95 \%$ significance. The arrows indicate the warming events discussed in sections 3.2.1 and 3.2.3. The ellipse indicates the warm anomaly of AW discussed in section 3.2.2. On the PWI differences maps, areas where there was no SPaW on both periods are indicated in grey.

[16] Thus, our analysis of the two main sources of heat for the Arctic Ocean, SPaW and AW, revealed a different behaviour during the last decade. While the AW, deeper in the water column, exhibited no warming trend over that period, the SPaW temperature increased by a factor of 2 from 1997 to 2008, suggesting a potential and significant impact of the SPaW on the surface layers, in a region where the most intense summer sea ice melting was observed during the same period.

[17] Thereby, although we cannot confirm Polyakov et al. [2010b] results suggesting that the AW could be involved in the recent Arctic summer sea ice major retreat events, we tend to agree with Shimada et al. [2006] and Woodgate et al. [2010] who proposed that the SPaW could be a good candidate for explaining part of the recent drastic Arctic sea ice reduction in summer in the Canada basin, in addition to local seasonal solar heating of the upper ocean [Jackson et al., 2010; Toole et al., 2010].

[18] Acknowledgments. Many thanks to the people who accepted to share with us their CTD data. Among them are I. Ashik (Akademik Fedorov campaigns and NP35), G. Bjork (Oden, Beringia and Lomrog campaigns), I. Polyakov (NABOS), U. Schauer (Polarstern campaigns), J. Zhao (CHINARE 2008), T. Kikuchi (JAMSTEC buoys) and J.-L. Etienne (Polar Observer)... The Ice-Tethered Profiler data were collected and made available by the Ice-Tethered Profiler Program based at the Woods Hole Oceanographic Institution (http://www.whoi.edu/itp). JWACS 2002 data and SCICEX data were collected and made available by the Beaufort Gyre Exploration Program based at the Woods Hole Oceanographic Institution (http://www.whoi.edu/beaufortgyre) in collaboration with researchers from Fisheries and Oceans Canada at the Institute of Ocean Sciences. The NPEO Aerial Survey data and SHEBA data were provided by NCAR/EOL under sponsorship of the National Science Foundation (http://data.eol.ucar.edu/). Many data came from the DAMOCLES project funded by the European Union 6th Framework Programme for Research and Development. Thanks to Geovariances for ISATIS software. The $\mathrm{PhD}$ was supported by the AXA Research Fund. This paper publication was funded by the ACCESS project which is a European project supported within the Ocean of Tomorrow call of the European Commission 7th Framework Programme.

[19] The Editor thanks an anonymous reviewer for their assistance in evaluating this paper.

\section{References}

Aagaard, K., L. K. Coachman, and E. Carmack (1981), On the halocline of the Arctic Ocean, Deep Sea Res., Part A, 28, 529-545, doi:10.1016/ 0198-0149(81)90115-1.

Ivanov, V. V., I. V. Polyakov, I. A. Dmitrenko, E. Hansen, I. A. Repina, S. A. Kirillov, C. Mauritzen, H. Simmons, and L. A. Timokhov (2009), Seasonal oceanic variability off Svalbard in 2004-06, Deep Sea Res., Part I, 56, 1-14, doi:10.1016/j.dsr.2008.07.013.

Jackson, J. M., E. C. Carmack, F. A. McLaughlin, S. E. Allen, and R. G. Ingram (2010), Identification, characterization, and change of the near-surface temperature maximum in the Canada Basin, 1993-2008, J. Geophys. Res., 115, C05021, doi:10.1029/2009JC005265.

Jones, E. P., L. G. Anderson, and J. H. Swift (1998), Distribution of Atlantic and Pacific waters in the upper Arctic Ocean: Implications for circulation, Geophys. Res. Lett., 25, 765-768, doi:10.1029/98GL00464.

Karcher, M. J., and J. M. Oberhuber (2002), Pathways and modification of the upper and intermediate waters of the Arctic Ocean, J. Geophys. Res., 107(C6), 3049, doi:10.1029/2000JC000530.

McLaughlin, F. A., E. C. Carmack, and R. W. Macdonald (1996), Physical and geochemical properties across the Atlantic/Pacific water mass front 
in the southern Canadian basin, J. Geophys. Res., 101(C1), 1183-1197, doi:10.1029/95JC02634.

McLaughlin, F. A., E. C. Carmack, R. W. Macdonald, H. Melling, J. H Swift, P. A. Wheeler, B. F. Sherr, and E. B. Sherr (2004), The joint roles of Pacific and Atlantic origin waters in the Canada basin 1997-1998, Deep Sea Res., Part I, 51, 107-128, doi:10.1016/j.dsr.2003.09.010.

Morison, J., M. Steele, and R. Andersen (1998), Hydrography of the upper Arctic Ocean measured from the nuclear submarine U.S.S. Pargo, Deep Sea Res. Part I, 45, 15-38, doi:10.1016/S0967-0637(97)00025-3.

Orvik, K. A., and O. Skagseth (2005), Heat flux variations in the eastern Norwegian Atlantic current toward the Arctic from moored instruments, 1995-2005, Geophys. Res. Lett., 32, L14610, doi:10.1029/ 2005GL023487.

Polyakov, I. V., et al. (2005), One more step toward a warmer Arctic, Geophys. Res. Lett., 32, L17605, doi:10.1029/2005GL023740.

Polyakov, I. V., V. A. Alexeev, U. S. Bhatt, E. I. Polyakova, and X. Zhang (2010a), North Atlantic warming: Patterns of long-term trend and multidecadal variability, Clim. Dyn., 34, 439-457, doi:10.1007/s00382-0080522-3.

Polyakov, I. V., et al. (2010b), Arctic Ocean warming contributes to reduced polar ice cap, J. Phys. Oceanogr., 40, 2743-2756, doi:10.1175/ 2010JPO4339.1.

Quadfasel, D. A., A. Sy, D. Wells, and A. Tunik (1991), Warming in the Arctic, Nature, 350, 385, doi:10.1038/350385a0.
Shimada, K., F. McLaughlin, E. Carmack, A. Proshutinsky, S. Nishino, and M. Itoh (2004), Penetration of the 1990s warm temperature anomaly of Atlantic water in the Canada basin, Geophys. Res. Lett., 31, L20301, doi:10.1029/2004GL020860.

Shimada, K., T. Kamoshida, M. Itoh, S. Nishino, E. Carmack, F. McLaughlin, S. Zimmermann, and A. Proshutinsky (2006), Pacific Ocean inflow: Influence on catastrophic reduction of sea ice cover in the Arctic Ocean, Geophys. Res. Lett., 33, L08605, doi:10.1029/ 2005 GL025624.

Toole, J. M., M.-L. Timmermans, D. K. Perovich, R. A. Krishfield, A. Proshutinsky, and J. A. Richter-Menge (2010), Influences of the ocean surface mixed layer and thermohaline stratification on Arctic Sea ice in the central Canada basin, J. Geophys. Res., 115, C10018, doi:10.1029/ 2009JC005660.

Woodgate, R. A., T. J. Weingartner, and R. Lindsay (2010), The 2007 Bering Strait oceanic heat flux and anomalous Arctic sea ice retreat, Geophys. Res. Lett., 37, L01602, doi:10.1029/2009GL041621.

P. Bourgain and J. C. Gascard, LOCEAN, Université Pierre et Marie Curie, 4 Place Jussieu, F-75005 Paris CEDEX, France. (pablod@ locean-ipsl.upmc.fr) 